\title{
CAUSES AND PSYCHOSOCIAL CONSEQUENCES OF INTIMATE PARTNER VIOLENCE IN AMBO TOWN MARRIED WOMEN
}

\author{
MULISA FAYERA1, ABERA GETACHEW²
}

1Department of Psychology, Institute of Education and Behavioral Sciences, Ambo University, West Showa, Oromia, Ethiopia ${ }^{2}$ School of psychology, College of Education and Behavioral Studies, Addis Ababa University., Mulisa Fayera. Mail: mulisafayera2@gmail.com

Received: 10 June 2021, Revised and Accepted: 14 July 2021

\begin{abstract}
Intimate partner violence is a pattern of coercive tactics that can include physical, psychological, sexual, economic, and emotional abuses against intimate partners, with the goal of establishing and maintaining power and control. The aim of this study is to investigate intimate partner violence and associated factors in Ambo town. The participants of the study were household women between the age15 to 49. Data were collected by using both quantitative and qualitative methods. To collect the quantitative data, 389 household women of Ambo Town were randomly selected for closeended questionnaire. In qualitative method , 12 participants (six women were victims of IPV and six other married women) were purposely selected for semi structured and 10 key informants were also purposely selected for Focus group discussion. The data collected from the questionnaires were analyzed using descriptive and inferential statistical tools through SPSS.20 and the qualitative data was analyzed narratively. The results of the study demonstrated that from the total 389 sample, 343 women did not agree with their husband and only 46 women reported that they agree with their husband. This shows that there was a problem of disagreement between wives and their husbands. Besides, causes and psychosocial consequences of IPV were directly related with intimate partner violence.
\end{abstract}

Keywords: Cause, Consequence, Intimate Partner Violence

C 2021 The Authors. Published by Innovare Academic Sciences Pvt Ltd. This is an open access article under the CC BY license (http://creativecommons.org/licenses/by /4.0/) DOI: http://dx.doi.org/10.22159/ijss.2021v9i5.41790. Journal homepage: https://innovareacademics.in/journals/index.php/ijss

\section{INTRODUCTION}

Intimate partner violence is defined by WHO as any conduct in the c ontext of an intimate relationship that harms physically, psychologic ally, or sexually people, including acts of physical aggression, sexual coercion and mental malpractice and behavioral control [1].

Similarly [2] UN reports that violence against women means any gen der violence, including threats of such acts of coercion and arbitrary denial of freedom whether in the private or public sphere, resulting or likely resulting in bodily, sexual or psychological injury or sufferin g to women.IPV victims appear to suffer psychological harm and soci al embarrassment.

According to WHO research, "evidence suggests that women who are abused by their partners have higher levels of depression, anxiety, a nd phobias than non-abused women" [3].

Globally, one in 3 women (35 percent) globally has at some point in t heir life experienced either physical or sexual violence. [4] Has also s hown that up to 70 percent of women had suffered intimate partner physical or sexual violence in their lives.

Recent research reports show that over $64 \%$ of women in Africa hav e suffered intimate partner abuse at least once in their lives (UN Stat istics, 2015). The prevalence of violence against intimate partners in subSaharan Africa is recorded as $20 \%$ to $71 \%$.

In Ethiopia, it's obvious that unheard voices and unspeakable stories about partner violence in most families. It's believed usual to keep silent about this and to care for it by the elders who encourage toleration of any quarrels in connection as bad the violence between men and women can be. Serious attacks on acids and physical wounds by spouses were also reported that were not taken into account [5]

There are diverse research that are seen as proof for Ethiopia's social concern, Intimate Partner Violence. In their encounters with male partners, women especially feel uncomfortable and endangered. According to the study "Domestic abuse or domestic violence in the context of marriage or coexistence, pre-domestic relationships such as dating and post-domestic partnerships" conducted by the Ministry of Women, Children and Youth in Ethiopia, one of the most common forms of violence in the field of violence against women is for former partners that no longer live together [6].

In Ethiopia, 34\% of ever-married women have always experienced physical, sexual, or psychological violence by their current husband, and $27 \%$ have experienced physical, sexual, or psychological violence in the previous 12 months, with Oromia leading the way, followed by Harari (CSA, 2016). The problem of intimate partner violence was not unique to the Oromia regional state, and Ambo town was no exception. As a result, the focus of this study will be on the causes, psychological repercussions, and coping methods of IPV among women in Ambo town.

\section{Statement of the problem}

Along with women, there is violence. Intimate partner violence is the leading cause of community health problems and violations of women's human rights around the world. It is a marvel that can be found in all countries and among all socioeconomic, religious, and cultural groups. Women's empowerment remains a huge concern and threat due to violence against women and girls. Intimate Partner Violence, in particular, has exorbitant physical, psychological, and financial costs, with death being a frequent occurrence [1]. The dangers of psychological health are greater than the dangers of physical health. Depression, panic attacks, nightmares, restlessness, eating disorders, low self-esteem, psychogenic diarrhea, and other social problems can affect battered women [7]. Women who have been sexually abused are more likely to abuse alcohol and other drugs. Intimate partner violence or abuse against women is thought 
to be the result of a complex combination of risk and protective factors, ranging from broad social issues to specific risk factors.

IPV against women has an impact on all aspects of women's lives, including their autonomy, productivity, and quality of life. It carries the risk of a wide range of negative health consequences, including death. It is vital to recognize that IPV limits the range of alternatives available to women in practically every aspect of their lives, both public and private. It restricts their options, has a direct impact on their health, disrupts their lives, and, in the end, violence prevents women from fully participating in society [3].

Some studies have shown, in interacting with other factors, that urban residency is identified as a risk. In Addis Abeba, for example, the study showed that in recent years IPV crime has been increasing. This could be shown in the study as an increase in IPV crime or it could be caused by an increasing number of people reporting IPV cases to the police. The combined circumstances may also have led to the increase in the number of crimes [8].

Despite the fact that intimate partner abuse is a global issue that affects every woman's life, the study's conclusion will outline various coping solutions for this pressing issue. As a result, this research was conducted not only to gain a better understanding of the various causes and psychological implications of intimate relationship violence, but also to outline how to prevent intimate partner violence. Based on this idea the following problems were addressed in this thesis. These problems are:

- What are the socio-demographic factors associated with the IPV among the women of Ambo town?

- What are the causes of IPV among the women of Ambo town?

- What are the psychosocial consequences of IPV among the women of Ambo town?

- What are the existing prevention mechanisms of IPV among the women of Ambo town?

\section{General Objective of the study}

To investigate the Causes, psychosocial consequences and coping mechanisms of intimate partner violence in Ambo town.

\section{Specific Objectives of the study}

- To investigate the socio-demographic factors associated with the IPV among the women of Ambo town.
- To investigate the causes of IPV among the women of Ambo town.

- To examine psychosocial consequences of IPV in Ambo town.

- To assess the mechanisms of coping of IPV among the women of Ambo town.

\section{Limitation of the study}

The research study is limited to some victims of intimate partner violence or married women who are dwellers of Ambo town. It is believed that the research setting was convenient to identifying the potential participants to address the research questions. Moreover, due to time and resource constraints the study was based on small samples and limited information. It would have been better, if different institutional players, men and women from different social status have been included and also because of the constraints of time and resource this study takes in to consideration married women of their age 15-49.

\section{RESULTS}

Based on the data obtained from respondents the causes, psychosocial consequences and coping mechanisms of intimate partner violence can be interpreted by using descriptive statistics and binary logistic regression and chi-square test. In descriptive statistics the results explained in frequency, percentage, minimum, maximum and standard deviation. Binary logistic regression and chisquare test shows the relationship and the degree of relationship between intimate partner violence and the factors. The data was analyzed by using SPSS statistical software.

\section{The results of socio-demographic factors}

The demographic profile of the respondents was presented in this section. A personal profile of the 389 sample respondents were summarized in the form of frequencies and percentages for this study. These include: ages, religions, attending religious service, educational levels of husbands and wives as well as employment status of husbands and wives.

\section{Socio-demographic Information}

Three hundred eighty-nine women participated in the study. Their mean age was $37.48(\mathrm{SD}=8.24)$, ranging from $15-49$ years. Besides, religious, educational, and employment status of the respondents is presented here under in tables.

Table 4.1: Religious Background

\begin{tabular}{|c|c|c|c|}
\hline Religion & N (\%) & Attending religious service & $\mathbf{N}$ \\
\hline Orthodox & $256(65.8)$ & Daily & $24(6.16)$ \\
\hline Protestant & $109(28.02)$ & Once per week & $263(67.61)$ \\
\hline Muslim & $3(0.77)$ & Occasionally & $102(26.22)$ \\
\hline Catholic & 0 & Total & $389(100)$ \\
\hline Waqefata & $21(5.3)$ & & \\
\hline Total & $389(100)$ & & \\
\hline
\end{tabular}

As table 4.3: depict the majority of respondents are Orthodox Christians $(65.8 \%)$, which is followed by protestant $(28.02 \%)$ and waqefata constitute $5.39 \%$. No respondents reported having no religion because it is mostly very important aspect in Ethiopian socio-cultural life and also $67.61 \%$ of the respondents were attended their religious service at least once per week. This shows that Women were kept at subordinate position by using religion and culture as an excuse and they have also their own contribution in tolerance and response of intimate partner violence as the subordinate.

Concerning the education, respondents were asked about their educational level. Accordingly, table 4.4 shows that $46.78 \%$ of the respondents have finished primary education and $9.25 \%$ of the respondents have completed secondary education. A significant proportion of respondents, that is, $37.53 \%$ have no formal education.
On the other hand, among the respondents' husbands as indicated in Table $4.4,14.91 \%$ of them have above secondary educational level. Husbands that have no formal education constitute $11.82 \%$. It confirms the gap of education between men and women in Ethiopia. Literature also indicates low educational status has its own impact in the occurrence of intimate partner violence against women.

In order to understand the type of work, respondents were asked the type of work they do. As table 4.5: shows $34.96 \%$ of women respondents reported that they were engaged in petty trade, which are followed by farming activities $27.5 \%$. Regarding respondent's husbands work status, $43.95 \%$ of them were worked in different sectors by Employed which constituted professionals, which are followed by $24 \%$ farming activities. The table indicates that more women are engaged in informal activities because of their low educational and social status. 
Table 4.4: Frequency of the Educational status of the wife and husband

\begin{tabular}{|c|c|c|c|c|}
\hline \multirow[t]{2}{*}{$\begin{array}{l}\text { Educational } \\
\text { levels }\end{array}$} & \multicolumn{2}{|c|}{$\begin{array}{c}\text { Education of the } \\
\text { Wife }\end{array}$} & \multicolumn{2}{|c|}{$\begin{array}{c}\text { Education of the } \\
\text { husband }\end{array}$} \\
\hline & Frequency & Percent & Frequency & Percent \\
\hline $\begin{array}{l}\text { No formal } \\
\text { education }\end{array}$ & 146 & 37.53 & 46 & 11.82 \\
\hline $\begin{array}{l}\text { Primary (1-8 } \\
\text { grades) }\end{array}$ & 182 & 46.78 & 233 & 59.89 \\
\hline $\begin{array}{l}\text { Secondary (9-12 } \\
\text { grades) }\end{array}$ & 36 & 9.25 & 58 & 14.91 \\
\hline $\begin{array}{l}\text { Above secondary } \\
\text { (above 12) }\end{array}$ & 25 & 6.42 & 52 & 13.36 \\
\hline Total & 389 & 100 & 389 & 100 \\
\hline
\end{tabular}

\section{The Chi-square test results of socio-demographic factors}

Chi-square test is one of inferential statistics that used to test independence (test of association of attribute) and tests of homogeneity. The results of chi-square test shows weather there were association between intimate partner violence and Sociodemographic factors, Causes of IPV, Psychosocial consequences of IPV and Coping mechanisms of IPV at $95 \%$ of level of significance as stated in methodological parts. So, to answer for the research question number one, the results of chi-square tests of intimate partner violence and socio-demographic factors were explained by using table as follows.

Table 4.6: the chi-square summary results of socio-emographic factors

\begin{tabular}{llrrrr}
\hline No. & Variables & $\begin{array}{l}\text { Chi- } \\
\text { square }\end{array}$ & df & \multicolumn{1}{c}{ Asymp.Sig. } \\
\hline 1 & Age & 211.92 & 3 & 0.00 & \\
2 & Religion & 462.25 & 3 & & 0.00 \\
3 & $\begin{array}{l}\text { Attending religious } \\
\text { service }\end{array}$ & 247.25 & 2 & 0.00 \\
4 & $\begin{array}{l}\text { Education of the wife } \\
\text { Type of job of the wife }\end{array}$ & 157.68 & 3 & 0.00 \\
6 & $\begin{array}{l}\text { Education of the } \\
\text { husband }\end{array}$ & 211.46 & 3 & 0.00 \\
7 & $\begin{array}{l}\text { Type of job of the } \\
\text { husband }\end{array}$ & 234.30 & 5 & 0.00 \\
\hline
\end{tabular}

As indicated on table 4.6 all socio-demographic factors were significant at $5 \%$ level of significance. This indicate that there was strong relationship between intimate partner violence and age, religion, attending religious service, education of the wife, job types of the wife, education of the husband and type job of the husband.

When their age increases they understood different situation in their environments and can handle the problem they faced easily. This shows increment of age have great significant effects on intimate partner violence. Cornering the religion any respondents have not reported as they having no religion. This shows that religion was the most important aspect in Ethiopian socio-cultural life and many respondents were attended their religious service occasionally. Within the families who were follows their religion attentively, there were agreement between each other, but within those who don't follow well, there were disagreement.

In addition, education was another factor that has significant effects on intimate partner violence. If they learn they can easily overcome the problems they faced in their life by bringing solution for the problems. Education of husband also reduces the effects of intimate partner violence. If both wife and husband were educated they can understood the factors that disturbed them and can find the remedial action for the problems. Job of husband and wife also has significant effects on intimate partner violence. Since husband and wife follow their job day to day they may not have the time to disturb one another.

Education and income status of individuals in marriage were also again an important intervening factor for violence. If the woman is educated, she is more likely to know her rights and duties. The woman would be assertive and free from harmful myth and would defend her rights through all means. In fact it has been shown in the demographic and health survey that educated women are less likely to agree a man justified in abusing his wife for any reason compared to uneducated women.

In general there were significant effects between socio-demographic factors and intimate partner violence.

Table 4.5: Frequency of the Employment status of the wife and husband

\begin{tabular}{|c|c|c|c|c|}
\hline \multirow[t]{2}{*}{$\begin{array}{l}\text { Employment } \\
\text { status }\end{array}$} & \multicolumn{2}{|c|}{$\begin{array}{l}\text { Employment of the } \\
\text { Wife }\end{array}$} & \multicolumn{2}{|c|}{$\begin{array}{l}\text { Employment of the } \\
\text { husband }\end{array}$} \\
\hline & Frequency & Percent & Frequency & Percent \\
\hline no job & 79 & 20.30 & 34 & 8.74 \\
\hline $\begin{array}{l}\text { Trade } \\
\text { activities }\end{array}$ & 136 & 34.96 & 45 & 11.56 \\
\hline $\begin{array}{l}\text { Employed } \\
\text { into different } \\
\text { sectors }\end{array}$ & 16 & 4.11 & 171 & 43.95 \\
\hline $\begin{array}{l}\text { Farming } \\
\text { activities }\end{array}$ & 107 & 27.50 & 106 & 27.24 \\
\hline daily laborer & - & - & 2 & 0.51 \\
\hline other jobs & 51 & 13.11 & 31 & 7.96 \\
\hline Total & 389 & 100 & 389 & 100 \\
\hline
\end{tabular}

\section{The results of Causes of IPV}

In this section, women's response to the major causes of the IPV would be presented in detail. That means, the second research question of this study was answered in this section. Descriptive statistical analysis like frequency and percent as well as inferential statistics such as binary logistic regression and chi-square test were employed assessing the causes of IPV. Furthermore, the result of qualitative data was analyzed narratively at the end of this section.

\section{The descriptive results of causes of IP}

Depending on the above table the researcher summarized the causes of IPV in four major heading causes. These were socio-cultural causes, economic causes, drinking alcohol related causes and jealousy and sexual related problems. These causes were described as follow:

Frist, concerning the socio-cultural causes the highest number of the respondents was mentioned their answer in the scale of both often and sometimes. Specially, $66.6 \%$ and $67.9 \%$ of the respondents stated that gender specific socialization and the discriminated role given for women were often the causes for the Violence with their husbands respectively. So, this shows that socio-cultural factors were the common causes of the intimate partner violence.

Second, as the table 7 indicated that economic factors were also the basic causes for the intimate partner violence. $58.1 \%$ and $59.6 \%$ of the respondents responded that husband's controlling the economy and wife dependency on her husband was often the main causes for the creation of violence between husband and wife.

Third, based on the result of table 7 drinking alcohol was the cause for the intimate partner violence. $60.9 \%$ of the respondents were answered drinking alcohol sometimes became the main causes of intimate partner violence.

Fourthly, depending on the above table jealous and absence of express loving face sometimes became the causes of intimate partner violence and absence of keeping the sexual feeling of each other often the major cause of intimate partner violence.

In addition to the data gathered from questionnaires, in interview and focus group discussion participants were mentioned the major factors that cause intimate partner violence. These factors were: 


\begin{tabular}{|c|c|c|c|c|c|c|}
\hline \multirow[t]{3}{*}{ Items } & \multicolumn{6}{|c|}{ Scale } \\
\hline & \multicolumn{2}{|c|}{ often } & \multicolumn{2}{|c|}{ sometimes } & \multicolumn{2}{|c|}{ never } \\
\hline & $\mathrm{N}$ & $\%$ & $\mathrm{~N}$ & $\%$ & $\mathrm{~N}$ & $\%$ \\
\hline \multicolumn{7}{|l|}{ Socio-cultural causes } \\
\hline Gender specific socialization & 259 & 66.6 & 111 & 28.5 & 19 & 4.9 \\
\hline Customs of marriage & 90 & 23.1 & 220 & 56.6 & 79 & 20.3 \\
\hline Discrimination role given for women & 264 & 67.9 & 79 & 20.3 & 46 & 11.8 \\
\hline Cultural definition for sex & 240 & 61.7 & 121 & 31.1 & 28 & 7.2 \\
\hline culture of superiority of men & 256 & 65.8 & 93 & 23.9 & 40 & 10.3 \\
\hline \multicolumn{7}{|l|}{ Economic causes } \\
\hline Husband's controlling the economy & 226 & 58.1 & 116 & 29.8 & 47 & 12.1 \\
\hline Limited access to education & 99 & 25.4 & 248 & 63.8 & 42 & 10.8 \\
\hline Wife dependent on her husband & 232 & 59.6 & 79 & 20.3 & 78 & 20.1 \\
\hline Drinking Alcohol & 118 & 30.3 & 237 & 60.9 & 34 & 8.7 \\
\hline \multicolumn{7}{|l|}{ jealousy and the sexual related problems } \\
\hline Because he envying (jealousy) to me & 154 & 39.6 & 157 & 40.4 & 78 & 20.1 \\
\hline Because he doesn't express loving face & 108 & 27.7 & 187 & 48.1 & 94 & 24.2 \\
\hline absence of keeping the sexual feeling & 246 & 63.2 & 126 & 32.4 & 17 & 4.4 \\
\hline
\end{tabular}

Socio-Cultural factors: the finding indicates that the strength of cultural norms which supports men's violence against women and women's obligation to obey her husband. For example, over half of the women, in the study, believed that husbands have a right to abuse their wives. That means, even the opinion of women towards gender role expectation was aggravated the occurrence of intimate partner violence. The widespread acceptability of the circumstances where wife beating was justified as the extent to which intimate partner violence was conceptualized as a form of chastisement for female behavior that transgresses certain expectations. Thus, it was important that only knowing the other causes of intimate partner violence was not enough, but also working to change attitudes of the women on their rights in general was also an important.

It was said most violent incidents were precede by arguments, which could well stem from differences of opinions and disobediences (not fulfilling demands of husband). For instance, refusing sex was often mentioned as the reason of intimate partner violence. Concerning with this study, in Ethiopia, there were a number of proverbs that put down women's nature and capabilities in order to justify the social predominance of men over women.

For example, "The thought of women and the light of star did not take one far". Thus, women were thought and expected to be submissive, passive, dependent and obedient to men. If they were disobedient, men would be used violence to discipline and maintain control.

Economic Causes of IPV: Participants frequently mentioned economic problem as the main causes of IPV. They pointed out that how their dependency on husband's income became worst and vulnerable to violence. This shows the subjugation of women emanates largely from the subordinate economic status.

Drinking alcohol: drinking alcohol was the other consistently mentioned reason for intimate partner violence. As drinking the alcohol have an impact on the economy, excessive consumption of alcohol have also been noted as a factor in provoking aggressive and violent male behavior towards women. The finding revealed that most cases of abuse were associated with the husband's excessive alcohol consumption. It was apparent that the participants consider alcoholism plays a role in violence, but is certainly not a simple cause. It was answered that men might come home drunk when they have some misunderstanding with their wives thereby they would got courage to say what they want and even assault their wives physically and psychologically as well as sexually.

Jealousy: It was also revealed that jealousy on the part of the aggressor can provoke violent behavior too. Both the survey and qualitative information showed that jealousy can lead to the occurrence of violence, specially, for women who were at young age. The respondents said that their husband's jealousy felling and accusations, justify their attitude in isolate from fiends, neighbor and family.
Generally, both the qualitative and quantitative findings of this study indicate that there were contributory conditions to the occurrence of intimate partner violence against women. Contributory conditions were a set of conditions which give rise to disagreements between a husband and wife. This includes socio-cultural factors, economic reason, drinking and jealousy and sexual related problems.

\section{DISCUSSION}

The Study finding shows that intimate partner violence is a broad term which includes different types of violence at household level. The socio-demographic characteristics of the respondents have their own influence for the creation of intimate partner violence. The ages, the educational levels, the employment status and the religion of the respondents have their own contribution for the increment or curbing the violence. Based on this research as age and educational level increase as well as when there is accessible job opportunity and when people follow their religion the chance for violence would be decrease. Literature review also indicates that younger age is associated with greater intimate partner violence perpetration or youth is highly associated with more frequent criminality [9] and [10]. The other literature also shows that when women have their own source of income the vulnerability of violence would be lower [9]. So, the result of this study is directly consistent with the literature.

The study also indicated that there were many reasons for the creation of Intimate Partner Violence. Based on this finding sociocultural factor, economic factor, alcohol drinking and jealousy as well as sexual related problems were the main causes of intimate partner violence.

The different Literature reviews also improve the consistency of this study. These literatures suggested that violence against women was most common in societies where gender roles were rigidly defined and enforced, and where the concept of masculinity was linked to toughness and male dominance $[11,12] \ldots$

The other literature which supports this study was stated that women living in economic problem suffer disproportionately [3]. Population based surveys from Brazil, Cambodia, Canada, Chile, Colombia, Costa Rica, El Salvador, India, Indonesia, Nicaragua, South Africa, Spain and Venezuela found a relationship between a woman's risk of suffering violence and her partner's drinking habits [13]. So, the results of this finding were consistent with the above stated literatures.

Concerning the psychosocial consequences of this finding, survivors of intimate partner violence were suffered from psychological challenges and social phobia. Some of the main behaviors that they were diagnosed for are depression, stress, anger, sorrow and related post traumatic behaviors. Most of them have low self-esteem and they recognize feelings of deceived, trauma, sadness and similar behaviors as it is investigated in other studies of the empirical literature. The [3] which declares the result being the experience of 
abuse often erodes women's self-esteem and puts them at the greater risk of a variety of mental health problem including depression; anxiety and social chaos also support the result of this study.

\section{CONCLUSION AND RECOMMENDATIONS}

\section{CONCLUSIONS}

Intimate Partner Violence is a very serious social issue which led into social chaos. Women could be affected physically, socially, psychologically or emotional as a result of intimate partner violence. Findings of this study also indicated that intimate Partner violence was a very complex process and influenced by multiple factors. There were different causes of intimate partner violence in the world. Based on this study socio-cultural factor, economic factor, alcohol drinking and jealousy as well as sexual related problems were the main causes of intimate partner violence.

The potential dangerousness of the intimate partner violence against women occurs throughout their marital lives. As it was indicated in this finding that woman who just survived in abusive relationship have signs of depression, hopelessness, lack of satisfaction, low selfesteem, sleeping problems, panic disorders, antisocial behavior, suicidal behavior, replaying assault in the mind, stress (anxiety), absence of sexual feeling, unintended pregnancy, restricted access to social services, isolation from social networks, gastrointestinal disorders, migraines and headaches and heart disease and so on as a result of losing control and interest in one's life. In addition many women were lived in fear not only for their own lives but also for the lives of their children.

This study also finds out that the ways of preventing the problems of intimate partner violence. The possible ways in which women saved themselves from the influences of intimate partner violence were through accepting the problem as it is, through the intervention of legal bodies and the kwon elders, through making a plan of action to curb the violence, through Positive reframing, through getting advice from someone what to do and so on were the most important coping mechanisms.

\section{Recommendations}

As this Study clearly demonstrates, intimate partner violence was an extreme manifestation of gender inequality that needs to be addressed urgently. Therefore, it is important to promote gender equality and human rights; train social, political, and religious leaders on the prevention of IPV; and strengthen formal and informal support systems for women living with violence. Besides, governmental and non-governmental agencies should sensitize legal and justice systems to the particular needs of women victims of violence.

\section{REFERENCE}

1. Abeya, S. G., Afework, M. F., \&Yalew, A. W. (2011). Intimate partner violence against women in western Ethiopia: prevalence, patterns, and associated factors. BMC public health, 11(1), 913.

2. Dibaba, Y. (2006). Prevalence of intimate partner physical violence against women and associated factors in Kofale district, Arsi zone, central Ethiopia. Ethiopian Journal of Health Sciences, 16(2).

3. Hague, G \& Wilson, C, (2000), 'The Silenced Pain: domestic violence 1945-1970' Journal of Gender Studies, 9:2, 157-169

4. Hurissa, B. F., Tebeje, B., \&Megersa, H. (2014).Prevalence of Pre-marital Sexual Practices and Associated Factors among Jimma Teacher Training College Students in Jimma Town, south west Shoa Zone, Oromiya Region, Ethiopia-2013.J Women's Health Care, 4(221), 2167-0420.

5. Megersa D.F. (2014).The Ethiopia's Legal frame work on domestic violence against Women: A critical Perspective: International Journal of gender and women's studies, 2(1), 4960.

6. MOWCYA.(2015). Assessment of Conditions of Violence against Women in Ethiopia.Addis Ababa, Ministry of Women, Children and Youth Affairs.

7. Regassa, N. (2012). Intimate partners violence in Southern Ethiopia: Examining the prevalence and risk factors in the Sidama zone. International Journal of Sociology and Anthropology, 4(1), 13-22.

8. Sosna M. (2007). Domestic Violence against women: The case of Kolfe keranyo Sub-City. Addis Ababa University, Addis Ababa.

9. Stockman, J. K., Lucea, M. B., \& Campbell, J. C. (2013). Forced sexual initiation, sexual intimate partner violence and HIV risk in women: a global review of the literature. AIDS and Behavior, 17(3), 832-847.

10. UN.(1993). Declaration on the Elimination of Violence against women. Paper presented at the proceedings of the 85th plenary meeting, Geneva.

11. W/Giorgis, EmebetKebede, and Melesse Damte.(2005). Violence against women in Addis Ababa.Berchi the annual journal of EWLA 2004; Addis Aabab, 5.

12. WHO. (2002) Understanding and addressing intimate partner violence and World Report on Violence and Health.

13. WHO.(2005). Multi-Country Study on Women's health and Domestic violence against women.Geneva, World Health organization. 